\title{
Research on extracting suspended particle matter content (SPM) based VNRedSat-1 imagery for monitoring water quality
}

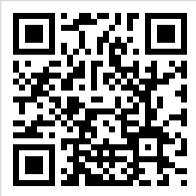

\author{
Ha Thanh Tran $1{ }^{*}$, Ngoc Minh Nguyen ${ }^{2}$, Ngoc Thi Tran ${ }^{3}$ \\ ${ }^{1}$ Faculty of Geomatics and Land Administration, Hanoi University of Mining and Geology, Vietnam \\ ${ }^{2}$ Centre of Control and Exploitattion Small Satellite, Space Technology Institute, Vietnam \\ ${ }^{3}$ Faculty of Environment, Hanoi University of Mining and Geology, Vietnam
}

\section{ARTICLE INFO}

Article history:

Received 15 th Aug. 2020

Revised 23 ${ }^{\text {rd }}$ Sep. 2020

Accepted $31^{\text {st }}$ Oct. 2020

Keywords:

SPM,

Suspended Particulate Matter,

Thi Vai River,

VNRedSat-1.

\section{ABSTRACT}

Currently, VNREDSAT 1 data have been commonly applied in studying disciplines of landscapes or socioeconomy. Nevertheless, there are limited studies using these data in water quality management. This article focuses on estimating amounts of SPM (Suspended Particulate Matters) from VNREDSAT 1 in Thi Vai river basin based on a popular formula with on - site adjustments. Results were validated by field data with an relative value $R^{2}=0.79$. This value represents that there is a potential of applying VNREDSAT 1 in studying SPM in water depending on certain circumstances of accuracy.

Copyright (C) 2020 Hanoi University of Mining and Geology. All rights reserved.

${ }^{*}$ Corresponding author

E - mail: tranthanhha@humg. edu.vn

DOI: 10. 46326/JMES. 2020.61(5). 03 


\title{
Tạp chí Khoa học Kỹ thuật Mỏ - Địa chất
}

Trang điện tử: http://tapchi.humg.edu.vn

\section{Nghiên cứu chiết tách hàm lượng chất lơ lửng (SPM) trên ảnh VNRedSat-1 hỗ trợ công tác giám sát chất lượng nước}

\author{
Trần Thanh Hà $1^{1,}$, Nguyễn Minh Ngọc ${ }^{2}$, Trần Thị Ngọc ${ }^{3}$ \\ ${ }^{1}$ Khoa Trắc địa - Bản đồ và Quản lý đất đai , Trường Đại học Mỏ - Địa chất, Việt Nam \\ 2 Trung tâm Điều khiển và Khai thác vệ tinh nhỏ, Viện Công nghệ vũ trụ, Việt Nam \\ ${ }^{3}$ Khoa Môi truờng, Truờng Đại học Mỏ - Địa chất, Việt Nam
}

THÔNG TIN BÀI BÁO T TÓM TẮT

Quá trình:

Nhận bài 15/8/2020

Sửa xong 23/9/2020

Chấp nhận đăng 31/10/2020

Tù̀ khóa:

Hàm lượng chất lơ lửng,

Lưu vực sông Thị Vải,

SPM,

VNRedSat-1.
Dũ liệu ảnh VNRedSat - 1 mặc dù đã được sử dụng khá phổ biến trong nghiên cúu thành lập bản đồ lớp phủ hay trong lĩnh vực kinh tế xã hội, tuy nhiên trong nghiên cứu chất lượng nước vẫn còn hạn chế. Bài báo này trình bày thư nghiệm tính hàm lượng chất lơ lửng SPM (Suspended Particulate Matter) từ dũ liệu VNRedSat - 1 cho lưu vực sông Thị Vải, sử dụng các công thức đã công bố và hiệu chỉnh cho phù hợp với điều kiện thực tếc của khu vực nghiên cúu. Kết quả sau khi tính toán đã được so sánh với số liệu đo thực địa và tương quan giữa giá trị thực đo và trên ảnh là $R^{2}=0,79$. Với kết quả trền đã chứng minh tính khả thi của việc ứng dụng ảnh VNRedSat - 1 vào nghiên cứu về phân bố hàm lượng SPM.

(C) 2020 Trường Đại học Mỏ - Địa chất. Tất cả các quyền được bảo đảm.

\section{Mở đầu}

Dựa trên các đặc điểm hóa học vật lý và sinh học của nước, việc đo đạc và đánh giá các tính chất của nước cần thực hiện nhằm phù hợp với từng mục đích sử dụng. Có rất nhiều chỉ tiêu và tính chất được sử dụng để xác định chất lượng nước, như: màu, hàm lượng ôxy hòa tan, tính dẫn điện, độ cứng, $\mathrm{pH}$, độ mặn, hàm lượng vật chất lơ lửng (Suspended Particulate Matter_SPM), chất hữu cơ hòa tan có màu (Colored Dissolved Organic Matters _CDOM) (Hoàng Văn Huệ, 2002) . Trong đó, để kiểm soát môi trường nước cần phải biết

*Tác giả liên hệ

E-mail: tranthanhha@humg.edu.vn

DOI: 10. 46326/JMES. 2020. 61 (5) . 03 hàm lượng vật chất lơ lửng (SPM) và phân bố không gian của nó. SPM là một trong ba thành phần chính trong nước tự nhiên, là chỉ số đại diện tổng hàm lượng các vật chất vô cơ và vật chất hữu cơ trong nước, chính vì vậy khi đánh giá chất lượng nước cần phải đánh giá chỉ số này trước tiên (Coleman, 2007).

Công nghệ viễn thám được sử dụng rộng rãi để đánh giá và thành lập bản đồ hàm lượng SPM ở nhiều độ phân giải không gian và thời gian khác nhau. Về mặt lý thuyết, một kênh đơn lẻ cũng có thể cung cấp thuật toán mạnh để xác định hàm lượng SPM trong nước. Tuy nhiên, các chất phức tạp trong nước làm thay đổi phản xạ phổ của nước, vì vậy dẫn đến sự khác nhau về màu sắc, do đó các kênh phổ khác nhau có thể được dùng để phục hồi hàm lượng SPM. Lợi thế của việc sử dụng kênh phổ hay tỉ số kênh có thể thu được kết quả 
chính xác hơn ở các hàm lượng khác nhau trong nước (D'Sa và Miller, 2005). Trong vùng cận hồng ngoại và hồng ngoại trung, nước hấp thụ ánh sáng mạnh hơn và làm cho nước nhìn tối hơn, các thay đổi này phụ thuộc và độ sâu của nước và bước sóng ánh sáng tới. Sự gia tăng của các chất vô cơ hòa tan trong nước là nguyên nhân dẫn đến việc thay đổi phản xạ chuyển từ vùng xanh lá (nước trong hơn) sang vùng đỏ. D'Sa và Miller (2005) đã chỉ ra rằng, hàm lượng SPM có thể đo được khi sử dụng các kênh phổ trong vùng nhìn thấy và các kênh tỉ số khác nhau, ví dụ như: tỉ số giữa kênh xanh lá $(500 \div 600 \mathrm{~nm})$ và đỏ $(600 \div 700 \mathrm{~nm})$, tỉ số giữa kênh xanh lam $(400 \div 500 \mathrm{~nm}), \ldots$

Để thực hiện công tác giám sát chất lượng nước, một số nhà khoa học thường lựa chọn các loại dữ liệu ảnh viễn thám như: MODIS (Miller và McKee, 2004), NOAA AVHRR và SeaWiFS (Myint và Walker, 2002) Landsat (Arun, 2011), Sentinel 2 (Miguel và nnk., 2018) hay kết hợp giữa ảnh Landsat 8 và Sentinel để xác định các thông số chất lượng nước mặt khu vực khai thác bauxite (Nguyễn Viết Nghĩa và Trịnh Lê Hùng, 2020). Kết quả của các nghiên cứu đã chứng minh tính ưu việt của phương pháp viễn thám. Hiện nay, dữ liệu ảnh VNRedSat - 1 của Việt Nam có độ phân giải không gian cao, chi tiết hóa các đối tượng nghiên cứu và đang được các nhà khoa học trong nước nghiên cứu ứng dụng trong một số lĩnh vực như: nghiên cứu lớp phủ mặt đất (Phạm Thị Làn và nnk., 2020) hay các lĩnh vực kinh tế xã hội (Chu Xuân Huy và nnk., 2018), tuy nhiên trong nghiên cứu chất lượng nước vẫn còn hạn chế. Ngoài ra, trong nghiên cứu của tác giả Nguyễn Văn Thảo (2016) đã sử dụng ảnh VNRedSat - 1 để nghiên cứu các thông số SPM và $\mathrm{Chl}$ - a cho khu vực ven bờ của đồng bằng châu thổ sông Hồng, sông Cưu Long và khu vực vịnh Hạ Long. Tuy nhiên, với khu vực cửa sông phức tạp như sông Thị Vải thì vẫn chưa có nhiều các nghiên cứu thử nghiệm.

Trong bài báo này, nhóm tác giả đã trình bày thực nghiệm sử dụng các ảnh vệ tinh VNRedSat 1 (mục 3. 1) được chụp ngày 15/4/2015 và ngày 22/4/2017 để xác định hàm lượng chất lơ lửng (SPM) trong nước và thành lập bản đồ hàm lượng SPM khu vực cửa sông Thị Vải, phục vụ công tác đánh giá hiện trạng môi trường nước.

\section{Khu vực nghiên cứu}

Sông Thị Vải có chiều dài 76 km, tiếp giáp với các tỉnh Bà Rịa - Vũng Tàu, Đồng Nai và Thành phố Hồ Chí Minh (TP. HCM); là sông nước mặn, ngắn, khá rộng và sâu, có thể coi là một vịnh hẹp ăn sâu trong đất liền, chịu ảnh hưởng của chế độ bán nhật triều rõ rệt (Trịnh Thị Long, 2008). Nhờ vị trí thuận lợi trong giao thông thủy bộ mà sông Thị Vải là khu vực rất hấp dẫn các nhà đầu tư. Các hoạt động kinh tế chủ yếu ở đây là công nghiệp, dịch vụ

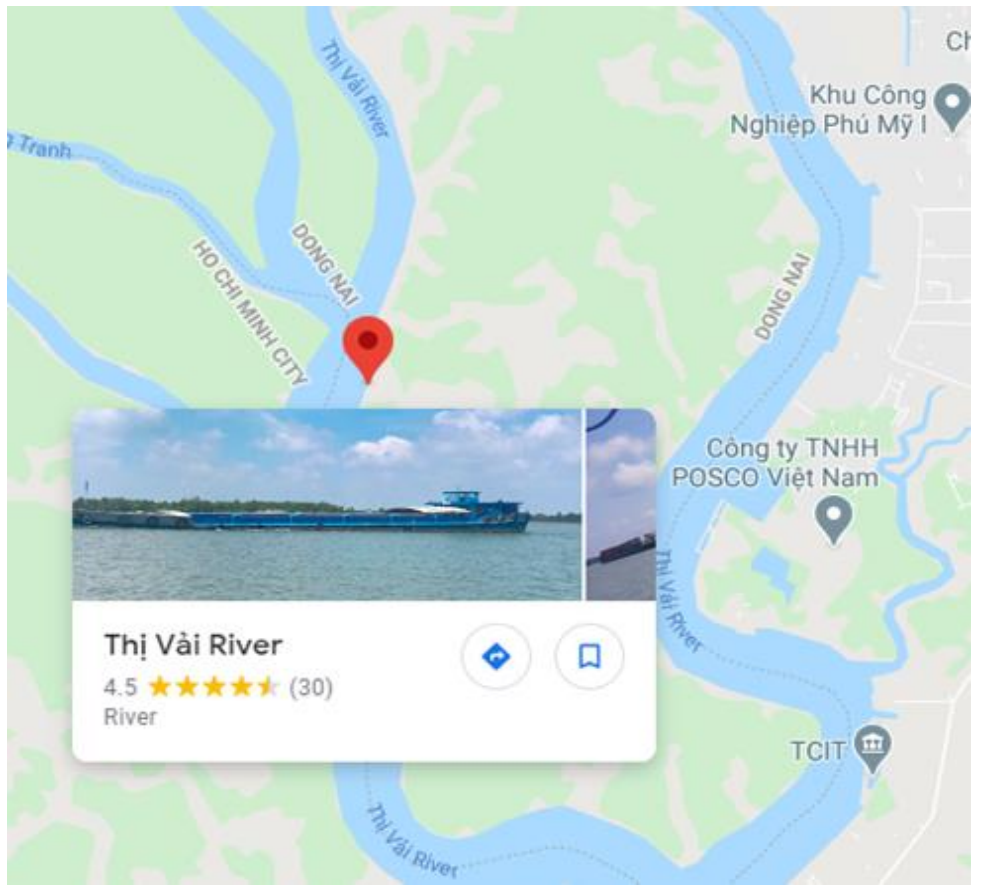

Hình 1. Bản đồ sông Thị Vải (https://directory. eoportal. org). 
cảng biển và dân cư sinh sống ven sông ngày càng phát triển. Nên sông đã bị ô nhiễm do phải tiếp nhận nước thải công nghiệp và sinh hoạt trong khu vực, nhất là thải từ các nhà máy (Trịnh Thị Long, 2008). Chính vì vậy việc theo dõi và quan trắc chất lượng nước tại sông Thị Vải rất quan trọng trong phát triển kinh tế.

\section{Dữ liệu và phương pháp nghiên cứu}

\section{1. Dũ liệu}

Trong phần thực nghiệm, nhóm tác giả đã thu thập một số cảnh ảnh VNRedSat - 1 phủ trùm khu vực nghiên cứu (Hình 2) với các thông tin mô tả trong Bảng 1 là các dữ liệu đa phổ, trong đó có một cặp ảnh mà thời gian chụp trùng với thời gian lấy mẫu thực địa (22/4/2017).

Với 4 kênh phổ Blue $(450 \div 520 \mathrm{~nm})$, Green $(530 \div 590 \mathrm{~nm})$, Red $(625 \div 695 \mathrm{~nm})$, NIR
$(760 \div 890 \mathrm{~nm}) \quad$ (https://directory. eoportal. org/).

\section{2. Phương pháp nghiên cúu}

Các dữ liệu thu thập được hiệu chỉnh hình học và đưa về hệ tọa độ UTM, WGS 84 múi 48. Sau đó, tiến hành hiệu chỉnh khí quyển và tính chuyển sang giá trị phản xạ phổ bề mặt theo các công thức (1) và (2).

Tính chuyển giá trị độ xám sang giá trị bức xạ theo công thức sau:

$$
R_{(p, b)}=\frac{Y_{(p, b)}}{K_{b}}
$$

Trong đó: $R_{(p, b)}$ - giá trị bức xạ thu được từ cảnh ảnh $\left(W /\left(\mathrm{m}^{2}\right.\right.$. sr. $\left.\left.\mu \mathrm{m}\right)\right) ; Y_{(p, b)}$ - giá trị tín hiệu đầu ra (LSB); $K_{b}$ - hệ số chuyển đổi chính xác đối với từng kênh (LSB/(W. m- $\left.{ }^{-2} \mathrm{sr}^{-1} \mu \mathrm{m}^{-1}\right)$ ).

Bảng 1. Các thông số của 4 cảnh ảnh VNRedSat-1 khu vực nghiên cúu.

\begin{tabular}{|c|c|c|c|c|c|}
\hline TT & Ngày chụp & Góc nghiêng dọc & Góc nghiêng ngang & Góc phương vị mặt trời & Góc cao mặt trời \\
\hline Cảnh 1 & $25 / 03 / 2015$ & 0,208397 & 2,218351 & 113,819340 & 67,104091 \\
\hline Cảnh 2 & $25 / 03 / 2015$ & 0,216239 & 2,213324 & 113,468877 & 67,143042 \\
\hline Cảnh 3 & $22 / 04 / 2017$ & 5,250607 & 25,672820 & 85,897008 & 67,904913 \\
\hline Cảnh 4 & $22 / 04 / 2017$ & 5,039313 & 25,692475 & 85,477888 & 67,867269 \\
\hline
\end{tabular}

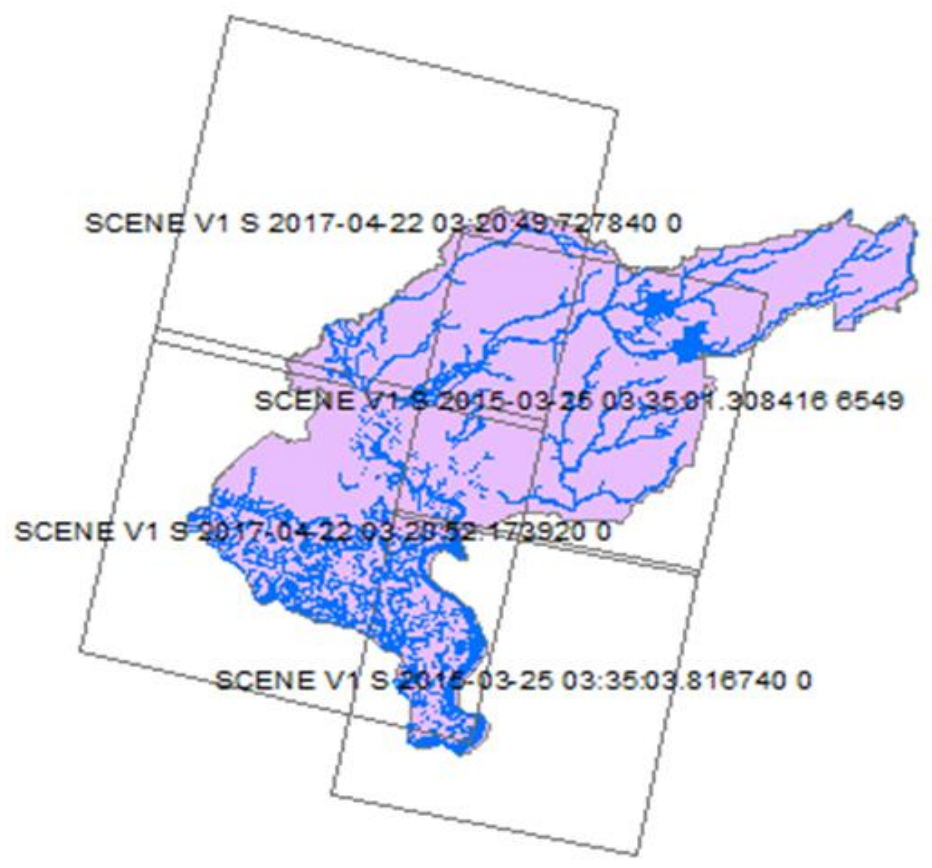

Hình 2. Sơ đồ cảnh ảnh phủ trùm lưu vực sông Thị Vải. 
Tính chuyển giá trị độ xám sang giá trị phản xạ phổ bề mặt:

$$
\rho_{(p, b)}=\pi \frac{R_{(p, b)}}{E_{b} \cos \theta_{s}} d_{s}^{2}
$$

Trong đó: $\rho_{(p, b)}$ - giá trị phản xạ phổ bề mặt $\left(s r^{-1}\right)$; $d_{s}$ - khoảng cách từ Trái đất đến Mặt trời theo đơn vị thiên văn; $\theta_{S}$ - góc cao mặt trời; $E_{b}$ - giá trị bức xạ mặt trời, đơn vị $\mathrm{W} /\left(\mathrm{m}^{2}\right.$. $\left.\mu \mathrm{m}\right)$.

Tiếp đến là phần tính hàm lượng SPM cho dữ liệu ảnh đã được hiệu chỉnh. Hầu hết các nghiên cứu hiện tại chỉ đề xuất mối quan hệ thực nghiệm giữa vật chất lơ lửng và phản xạ tại các kênh phổ vệ tinh khác nhau bằng cách so sánh hàm lượng vật chất lơ lửng đo đạc với số liệu chiết tách từ ảnh vệ tinh. Các nghiên cứu của tác giả Gordon, Wang (1994); Coleman, Roberts, (1989); Wang, (2009) chỉ ra rằng có sự tương đồng giữa các thuật toán trầm tích lơ lửng về dạng thức hoặc cách lựa chọn bước sóng. Điều này được quy cho nhiều yếu tố bao gồm biến đổi nồng độ trầm tích, biến đổi tính chất hạt như kích thước, hình dạng hoặc khoáng vật học, cùng với các lỗi phát sinh thông qua sự hiện diện của các thành phần trong nước cùng biến đổi (Antoine và nnk., 2011).

Tùy theo khu vực nghiên cứu mà hiện nay có khá nhiều thuật toán được các nhóm nghiên cứu trên thế giới phát triển như: Khu vực có trầm tích chi phối ánh sáng thì sử dụng các thuật toán dựa vào tỉ lệ các bước sóng trong dải nhìn thấy (Bricaud và nnk., 2002; Gohin và nnk., 2002; Babin và nnk., 2003). Phương pháp đáng tin cậy nhất cho khu vực có phù sa lơ lửng trong vùng có độ đục vừa phải là sử dụng phản xạ kênh đơn mà không phải là tỷ lệ kênh phản xạ (Gordon và Wang, 1994); Biển Bắc (Coleman và Roberts, 1989); vịnh Biscay (Gordon và McCluney, 1975) và biển Ailen (Holm-Hansen và nnk., 1965).

Do sự thay đổi kích thước và kiểu hạt gây ảnh hưởng mạnh đến tán xạ và phản xạ dẫn đến việc các thuật toán phản xạ đơn giản có sai số đáng kể (Huot và nnk., 2008). Để giải quyết vấn đề này, một số nghiên cứu đề xuất rằng những biến đổi phản xạ do thay đổi đặc điểm hạt có thể tránh được bằng cách sử dụng tỷ lệ phản xạ (Kirk, 1994). Từ đó, mô hình quang học từ việc giải phương trình truyền bức xạ do Gordon thực hiện năm 1975 đã được đưa ra, trong đó cho phép giá trị phản xạ được mô tả dưới dạng tính chất quang học phụ thuộc, hấp thụ và tán xạ ngược (Gordon,
1975; Wang, 1994; IOCCG, 2000). Sự đóng góp của các thành phần khác nhau đến hệ số hấp thụ và tán xạ được được mô tả về hai thành phần hệ số hấp thụ xác định $\left(a^{*}\right)$ và hệ số tán xạ ngược $\left(b^{*}\right)$ cho mồi vật liệu hạt riêng biệt theo phương trình (3) và (4).

$$
\begin{aligned}
a_{(\lambda)}=a_{W(\lambda)}+ & a_{Y S(\lambda)}^{*}[Y S]+a_{M S S(\lambda)}^{*}[M S S] \\
& +a_{C(\lambda)}^{*}[C] \\
b_{b(\lambda)}=a_{b W(\lambda)}+ & b_{b M S S(\lambda)}^{*}[M S S]+b_{b C(\lambda)}^{*}[C]
\end{aligned}
$$

Trong đó: $W, M S S, Y S$ và $C$ - nước, trầm tích lơ lửng, chất màu vàng và sinh vật phù $\mathrm{du}, \lambda$ - bước sóng phụ thuộc vào tính chất quang học phụ thuộc và các dấu ngoặc vuông đại diện cho nồng độ của từng chất, mg/l.

Để tính toán hàm lượng SPM, nhóm tác giả sử dụng công thức đã được áp dụng đối với lưu vực sông Mê Kông (Kummu và nnk., 2010) như sau:

$$
S P M=a e^{b R_{i}}
$$

Trong đó: $R_{i}$ - phản xạ của nước tại các bước sóng.

$$
R_{i}=S M I_{S} P_{S i}+S M I_{w} P_{w i}
$$

$S M I_{w}$ và $S M I_{s}$ - chỉ số phổ của chất lơ lửng và nước, liên quan trực tiếp đến khối lượng/nồng độ, được ước tính bằng cách giải hệ phương trình (6) theo phương pháp bình phương tối thiểu, với i là số lượng các kênh phổ; $P_{w}$ - phổ phản xạ tiêu chuẩn của nước được đo bằng bức xạ quang học trong phòng thí nghiệm; $P_{i}$ - phổ phản xạ của chất lơ lửng, được đo bằng phương pháp đo phản xạ trầm tích khô để đại diện cho các trầm tích lơ lửng tiêu chuẩn.

\section{Kết quả và thảo luận}

Các dữ liệu ảnh thu thập ở mức $1 \mathrm{~A}$, sau đó được hiệu chỉnh hình học, hiệu chỉnh khí quyển, tính chuyển về giá trị phản xạ và tính toán giá trị SPM. Kết quả thu được thể hiện như Hình 3 và Bảng 2 .

Để đánh giá độ chính xác của thuật toán khi áp dụng vào dữ liệu ảnh VNRedSat-1, nhóm nghiên cứu đã tiến hành lấy mẫu thực địa (vào đúng ngày chụp ảnh 22/4/2017) và phân tích theo phương pháp của Servais đề xuất năm 1995. Nguyên tắc của phương pháp này là: Dùng máy lọc chân không hoặc áp suất để lọc mẫu qua phin lọc sợi thủy tinh. Sấy phin lọc ở $105^{\circ} \mathrm{C}$ và lượng cặn được xác định bằng cách cân. 


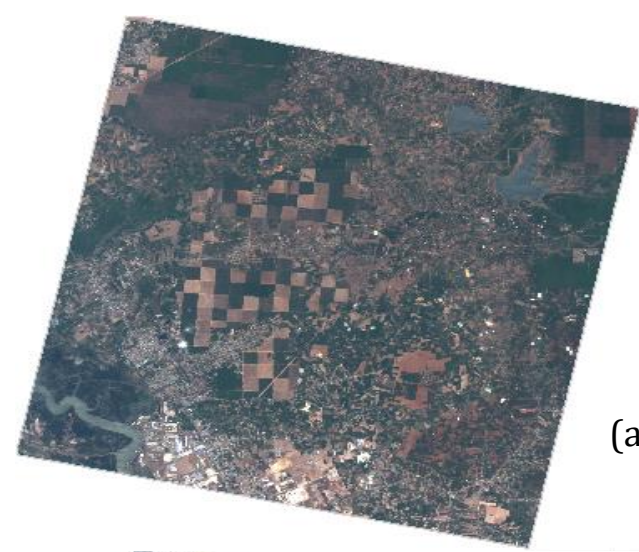

(a)
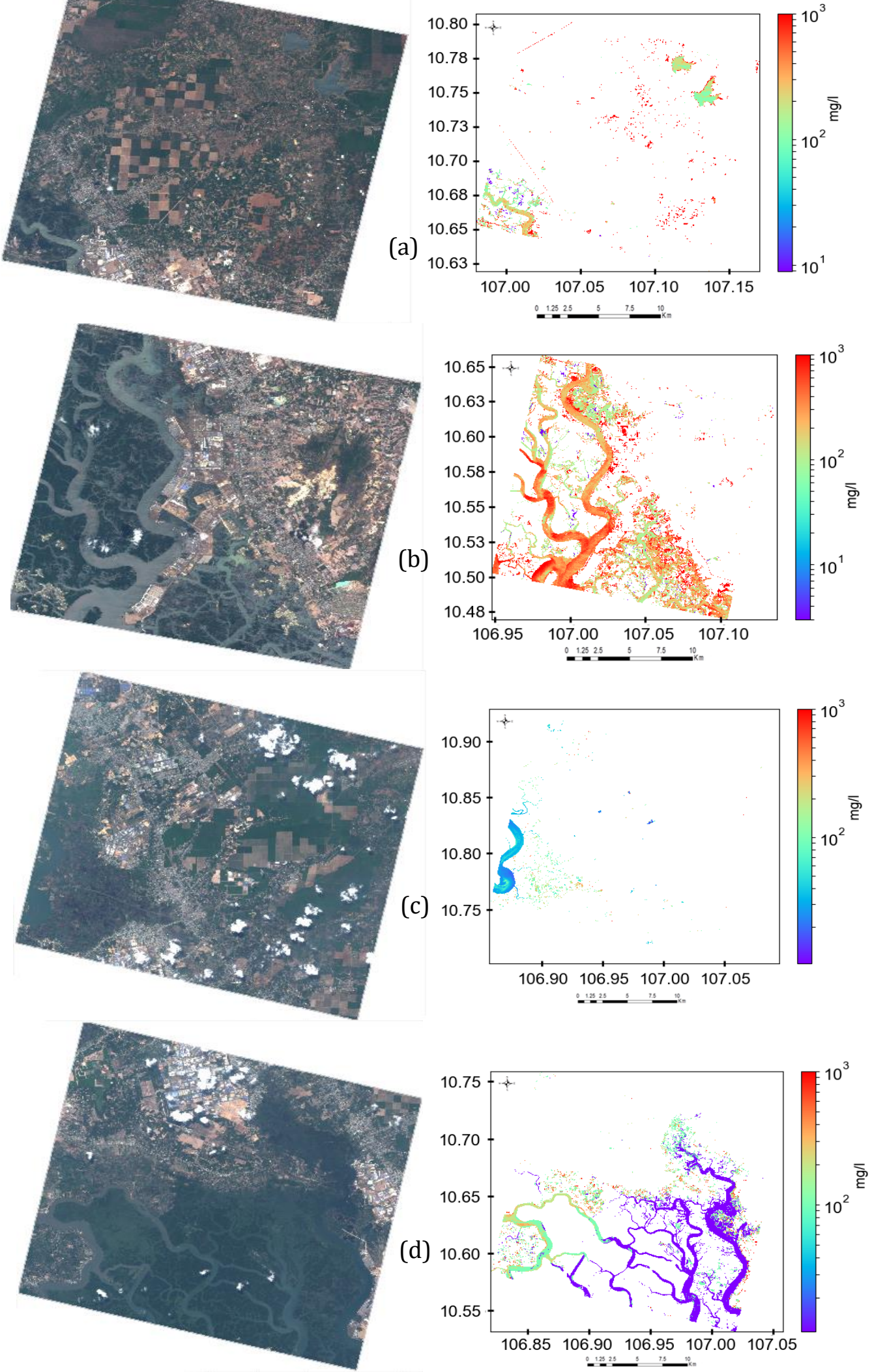

Hình 3. Bản đồ SPM của tùng cảnh ảnh. (a) Ảnh đã hiệu chỉnh và SPM - Cảnh 1; (b) Ảnh đã hiệu chỉnh và SPM - Cảnh 2; (c) Ảnh đã hiệu chỉnh và SPM - Cảnh 3; (d) Ảnh đã hiệu chỉnh và SPM - Cảnh 4. 
Bảng 2. Giá trị SPM thực địa và trên ảnh (đon vị mg/l).

\begin{tabular}{|c|c|c|c|c|c|c|c|c|}
\hline TT & $\begin{array}{c}\text { Kết quả đo } \\
\text { thực địa }\end{array}$ & $\begin{array}{c}\text { Kết quả đo } \\
\text { trên ảnh }\end{array}$ & TT & $\begin{array}{c}\text { Kết quả đo } \\
\text { thực địa }\end{array}$ & $\begin{array}{c}\text { Kết quả đo } \\
\text { trên ảnh }\end{array}$ & TT & $\begin{array}{c}\text { Kết quả đo } \\
\text { thực địa }\end{array}$ & $\begin{array}{c}\text { Kết quả đo } \\
\text { trên ảnh }\end{array}$ \\
\hline 1 & 42,796 & 40,425 & 8 & 45,863 & 40,425 & 15 & 30,087 & 27,359 \\
\hline 2 & 39,421 & 40,425 & 9 & 37,378 & 39,120 & 16 & 34,761 & 32,100 \\
\hline 3 & 37,675 & 36,903 & 10 & 40,091 & 36,555 & 17 & 32,603 & 36,404 \\
\hline 4 & 35,697 & 34,926 & 11 & 27,751 & 24,000 & 18 & 39,48 & 35,699 \\
\hline 5 & 19,987 & 22,171 & 12 & 29,541 & 32,18 & 19 & 26,897 & 22,254 \\
\hline 6 & 31,098 & 34,511 & 13 & 20,001 & 23,119 & 20 & 25,034 & 27,671 \\
\hline 7 & 30,213 & 26,342 & 14 & 36,763 & 40,425 & 21 & 27,615 & 23,000 \\
\hline
\end{tabular}

Các điểm lấy mẫu thực địa để kiểm chứng kết quả được lấy trong giới hạn của một cảnh ảnh chụp ngày 22/4/2017. Tuy nhiên, thời gian lấy mẫu có sự khác biệt và dao động trong khoảng từ $9 \div 15$ h. Đây là thời điểm thủy triều trong khu vực hoạt động yếu nhất trong ngày nên đảm bảo độ tin cậy, đồng thời đây cũng là khoảng thời gian thích hợp để thu được năng lượng phản xạ từ mặt trời lớn nhất. Do các điểm thực địa trải rộng nên tính đồng nhất giữa các điểm cũng có ảnh hưởng nhất định đến kết quả phân tích như Bảng 3. Bên cạnh đó, các kết quả được thực hiện phân tích trong phòng thí nghiệm, không phải là đo trực tiếp tại điểm lấy mẫu, do vậy hoàn toàn có thể chịu thêm sai số phát sinh như các vi sinh vật trong nước bị chết,...

Các kết quả cũng thể hiện rõ sự khác nhau về hàm lượng chất lơ lửng khi chụp ảnh vào những thời điểm khác nhau. Cảnh 1 và 2 được chụp ngày 25/3/2015 trong khi cảnh 3 và 4 được chụp ngày 22/4/2017. Mặc dù nhóm tác giả đã lựa chọn dữ liệu trong cùng mùa nhưng sự khác nhau là rất rõ rệt. Trong khi cảnh 1 và 2 thể hiện hàm lượng SPM cao (trung bình khoảng $595 \mathrm{mg} / \mathrm{l}$ ); thì cảnh 3 và 4 thể hiện hàm lượng SPM thấp hơn nhiều (trung bình khoảng $71 \mathrm{mg} / \mathrm{l}$ ), trong đó khu vực có hàm lượng cao tập trung chủ yếu về phía tây lưu vực đây là nơi chịu ảnh hưởng từ việc xây dựng và hoạt động của cảng Cát Lái.

Hàm lượng SPM của các nhánh sông trên cùng một cảnh ảnh có sự khác biệt rõ rệt, ngay cả trên dữ liệu ảnh được tổ hợp màu tự nhiên cũng dễ dàng nhận ra được điều này. Trong hình dưới đây thể hiện một nhánh sông Đồng Tranh đổ ra sông Lòng Tàu, nhưng tại vị trí ngã ba sông, sự khác biệt là rất rõ rệt (Hình 5). Đây là tình trạng khá thường gặp ở đây khi mà lượng vật chất như phù sa,... từ thượng nguồn đổ ra biển nhưng khi đến khu vực cửa sông, gặp phải sự xâm nhập ngược từ biển vào gây nên hiện tượng này (Hình $5 b$ ). Trong Hình $5 a$ có thể thấy, hàm lượng SPM thay đổi khi tàu thuyền đi từ khu vực nước trong vào khu vực nước đục hơn trên cùng một nhánh sông.

\section{Kết luận}

Khu vực cửa sông luôn là nơi có hoạt động phức tạp, tạo nên sự thay đổi mạnh mẽ về giá trị SPM như trong Hình $5 b$; cụ thể là cùng một khu vực nhưng giá trị SPM thay đổi từ $27 \mathrm{mg} / \mathrm{l}$ đến $1114 \mathrm{mg} / \mathrm{l}$ chỉ trong vòng vài trăm mét, đây là do nước đổ từ thượng lưu ra biển mang theo nhiều phù sa,... làm cho giá trị SPM cao vượt trội so với nước biển xâm nhập từ biển vào, mang theo ít phù sa và nước khá trong. Điều này có thể dễ dàng nhận thấy bằng mặt thường qua sự thay đổi về màu sắc của nước trên ảnh.

Bên cạnh đó, sự hoạt động của tàu thuyền cũng dẫn đến hiện tượng có một khu vực dạng tuyến trên ảnh có giá trị SPM thấp hơn so với xung quanh. Trên Hình $5 \mathrm{a}$ có thể thấy một vùng có giá trị SPM khoảng $41 \mathrm{mg} / \mathrm{l}$ trong khi xung quanh là $101 \mathrm{mg} / \mathrm{l}$. Điều này được giải thích là do khi tàu thuyền hoạt động làm nước trên sông rẽ sang hai bên, dẫn đến các chất lơ lửng theo nước dạt về hai bên bờ, làm nước ở phần sau tàu sẽ trong hơn, làm giá trị SPM thấp hơn.

Tuy nhiên, chỉ sau một thời gian thì giá trị sẽ đồng đều trở lại. Đây là hai hiện tượng khá phổ biến tại khu vực cửa sông và hoàn toàn có thể dẫn đến nhầm lẫn khi thực hiện công tác chiết tách thông tin sau khi phân tích ảnh. Nhất là đối với khu vực đồng bằng sông Cửu Long. 
Bảng 3. Sai số giữa kết quả đo thực địa và trên ảnh.

\begin{tabular}{|c|c|c|c|c|c|}
\hline TT & Sai số & TT & Sai số & TT & Sai số \\
\hline 1 & 2,371 & 8 & 5,438 & 15 & 2,728 \\
\hline 2 & $-1,004$ & 9 & $-1,742$ & 16 & 2,661 \\
\hline 3 & 0,772 & 10 & 3,536 & 17 & $-3,801$ \\
\hline 4 & 0,771 & 11 & 3,751 & 18 & 3,781 \\
\hline 5 & $-2,184$ & 12 & $-2,639$ & 19 & 4,643 \\
\hline 6 & $-3,413$ & 13 & $-3,118$ & 20 & $-2,637$ \\
\hline 7 & 3,871 & 14 & $-3,662$ & 21 & 4,615 \\
\hline
\end{tabular}

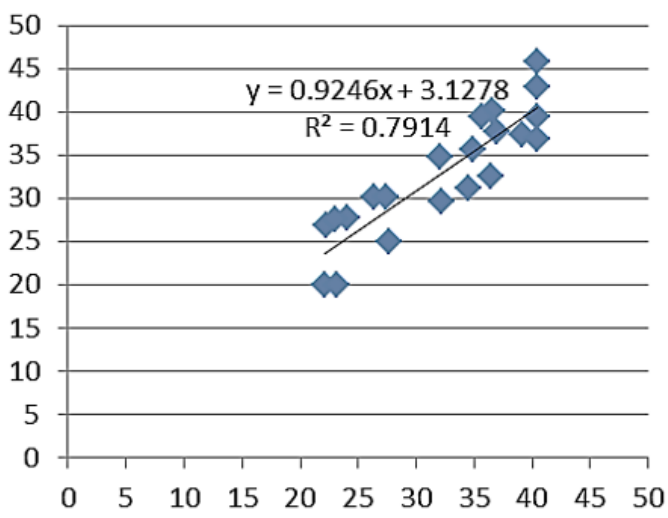

Hình 4. Hệ số tương quan giữa kết quả SPM thực địa và trên ảnh (tính theo mg/l).
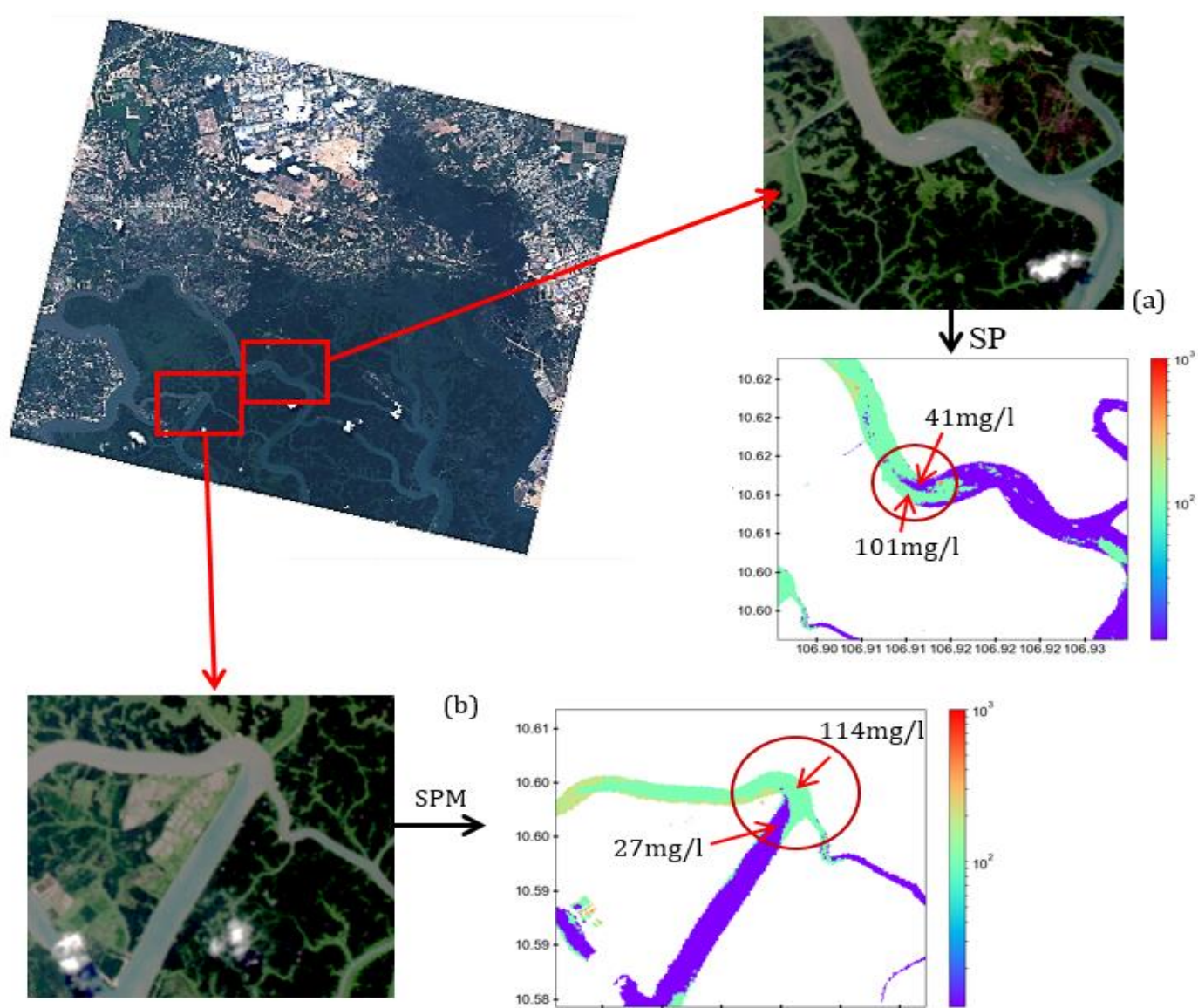

(b)

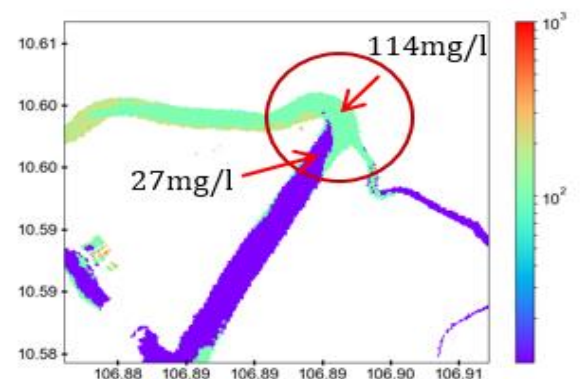

Hình 5. Sự thay đổi hàm lượng SPM do hoạt động của tàu thuyền (a) và xâm nhập mặn (b). 
Với hệ số tương quan thu được giữa giá trị đo thực địa và tính toán trên ảnh là $R_{2}=0,79$ (Hình 4) đã chứng minh tính khả thi của việc ứng dụng ảnh VNRedSat-1 vào nghiên cứu về phân bố hàm lượng SPM, đây cũng là một hướng mới và hiệu quả, vì nguồn dữ liệu này có độ phân giải không gian cao, cho phép chi tiết hóa và chính xác hóa những khu vực có diện tích nhỏ hay các khu vực sông nhỏ.

\section{Đóng góp của các tác giả}

Tác giả Trần Thanh Hà hình thành ý tưởng, triển khai các nội dung và hoàn thiện bài báo; tác giả Nguyễn Minh Ngọc cùng triển khai các nôi dung và đọc bản thảo bài báo; tác giả Trần Thị Ngọc giúp lấy số liệu kiểm chứng và tính toán.

\section{Tài liệu tham khảo}

Antoine, D., Siegel, D. A., Kostadinov, T., Maritorena, S., Nelson, N. B., Gentili, B., Vellucci, V. and Guillocheau, N., (2011). Variability in optical particle backscattering in three contrasting bio-optical oceanic regimes, Limnology and Oceanography, 56(3), 955-973.

Babin, M., Stramki, D., Ferrari, G. M., Claustre, H., Bricaud, A., Obolensky, G., and Hoepffner, N., (2003). Variations in the light absorption coefficients of phytoplankton, nonalgal particle, and dissolved organic matter in coastal waters around Europe, J. Geophys. Res., 108(C7), 3211.

Bricaud, A., Bosc, E., Antoine, D. (2002). Algal biomass and sea surface temperature in the Mediterranean Basin Intercomparison of data from various satellite sensors, and implications for primary production estimates. Remote Sensing of Environment 81, 163 - 178.

Chu Xuân Huy (2018). Ứng dụng ảnh viễn thám và GIS trợ giúp quản lý, qui hoạch trong một số khu vực phát triển trọng điểm của tỉnh Đồng Nai, mã số VAST. ĐNP. 06/16-17.

Coleman J., Roberts H., Stone, W., (1989). Mississippi River Delta: an Overview. Journal of Coastal Research 14(3).

D'Sa, E. J., and Miller, R. L., (2005). Bio-optical properties of coastal waters, in Remote Sensing of Coastal Aquatic Environments, edited by R. L. Miller, C. Del Castillo, and B. McKee, chap. 6, pp. 129-155, Springer, New York.

Dương Hữu Quốc, (2017). Khảo sát một số chỉ tiêu hóa lý(pH, TSS, COD, DO) và đánh giá chất lượng nước mặt trên lưu vực sông Thị Vải, Đồ án tốt nghiệp.

Gohin, F., Druon, J. N., Lampert, L., (2002). A five channel chlorophyll concentration algorithm applied to SeaWiFS data processed by SeaDAS in coastal waters remote sensing 23(8), 1639 1661.

Gordon, H., and McCluney, W., (1975). Estimation of the Depth of Sunlight Penetration in the Sea for Remote Sensing. Applied Optics 14(2), 413416.

Gordon, H., and Wang, M., (1994). A simple, moderately accurate, Atmospheric correction algorithm for SeaWiFS. Remote Sensing of Environment 50(3), 231-239.

Ha Thanh Tran, Tri Dinh Tran, Hai Minh Nguyen (2016). Towards integration of radar and optical imagery by applying IHS technique. Journal of Mining and Earth Sciences 56.

Hoàng Văn Huệ (2002). Xử lý nước thải. Nhà xuất bản Khoa học và Kỹ thuật, Hà Nội, Thoát nước tập 2.

Holm-Hansen O., Lorenzen C. J., Holmes R. W., Strickland, J. D. H., (1965). Fluorometric determination of chlorophyll. J. Cons. perm. int. Explor. Mer 30 (1), 3-15.

Https://directory. eoportal. org/web/eoportal /satellite-missions/v-w-x-y-z/VNRedSat-1

Https://www.google.com/maps/place/Th\%E1 \%BB\%8B+V\%E1\%BA\%A3i+River

Huot, Y., Morel, A., Twardowski, M. S., Stramski, D., and Reynolds, R. A., (2008). Particle optical backscattering along a chlorophyll gradient in the upper layer of the eastern South Pacific Ocean. Biogeosciences 5, 495-507.

IOCCG, (2000). Remote Sensing of ocean colour in coastal, and other optically-Complex, waters. Reports of the International Ocean-Colour Coordinating Group 3. 
Kummu, M., Lu, X. X., Wang, J. J., Varis, O., (2010). Basin-wide sediment trapping efficiency of emerging reservoirs along the Mekong. Geomorphology 119 (3-4), 181-197

Miller, R. L., and McKee, B. A., (2004), Using MODIS Terra $250 \mathrm{~m}$ imagery to map concentrations of suspended matter in coastal waters. Remote Sens. Environ., 93, 259-266.

Myint, S. W., and Walker, N. D., (2002), Quantification of surface suspended sediments along a river dominated coast with NOAA AVHRR and SeaWiFS measurements: Louisiana, USA, Int. J. Remote Sens., 23, 32293249.

Nguyễn Văn Thảo, (2016). Nghiên cứu các phương pháp phân tích, đánh giá và giám sát chất lượng nước ven bờ bằng tư liệu viễn thám độ phân giải cao và độ phân giải trung bình, đa thời gian; áp dụng thử nghiệm cho ảnh của vệ tinh VNREDSAT-1, đề tài cấp Viện Hàn lâm Khoa học và Công nghệ Việt Nam.
Nguyễn Viết Nghĩa, Trịnh Lê Hùng, (2020). Nghiên cứu xác định các thông số chất lượng nước mặt khu vực khai thác bauxite Tân Rai (Lâm Đồng) từ dữ liệu ảnh vệ tinh Sentinel-2 MSI và Landsat 8. Tạp chí khoa học Kỹ thuật Mỏ - Địa chất, Số 61(2).

Phạm Thị Làn, Nguyễn Phi Sơn, Nguyễn Viết Nghĩa, Đào Vân Hương, Doãn Đức Long, Võ Thị Hồng Nhung, Nguyễn Thị Thu Trang, Trần Văn Huân, Lê Thanh Nghị, (2020). Thành lập bản đồ lớp phủ bằng phương pháp phân loại hướng đối tượng áp dụng cho dữ liệu ảnh VNRedSat1. Tạp chí khoa học Kỹ thuật Mỏ - Địa chất 61(2).

Trần Thanh Hà, (2018). Phép biến đổi Wavelet trong phân tích tín hiệu ảnh Sar để xác định kích thước cửa số tối ưu cho quá trình đồng đăng ký ảnh. Tạp chí khoa học Kỹ thuật Mỏ - Địa chất 59(1).

Trịnh Thị Long, (2008). Vấn đề ô nhiễm sông Thị Vải. Viện Khoa học Thủy Lợi Miền Nam. 